\title{
Work in Harsh Hot Environment: Risk Evaluation on Thermal Stress in a Farm during Green Pruning Activity
}

\author{
Giuseppe Masanotti*1, Massimo Bartalini², Alessandro Fattorini ${ }^{2}$, Anna Cerrano ${ }^{2}$, Alessandro \\ Messeri $^{3}$, Marco Morabito ${ }^{4}$ and Serena Iacopini ${ }^{5}$ \\ ${ }^{1}$ Department of Experimental Medicine, Public Health Section, Italy \\ ${ }^{2}$ Workplace Health and Safety Unit (UF PISLL), Local health Agency (Azienda USL) Toscana sud est, Italy \\ ${ }^{3}$ Centre of Bioclimatology, Department of Agriculture, Food, Environment and Forestry (DAGRI) University of Florence, Italy \\ ${ }^{4}$ Institute of Biometeorology - National Research Council (IBIMET-CNR), Italy \\ ${ }^{5}$ Trainee Workplace Health and Safety Unit (UF PISLL), Local health Agency (Azienda USL) Toscana sud est
}

*Corresponding author: Giuseppe Masanotti, Department of Experimental Medicine, Public Health Section, University of Perugia, pz. Lucio Severi, 1, 06129 Perugia, Italy

\section{ARTICLE INFO}

Received: 彗 March 23, 2019

Published: 慧 March 28, 2019

Citation: Masanotti G, Bartolini M, Fattorini A, Cerrano A, Messeri A, Morabito $\mathrm{M}$ and Iacopini $\mathrm{S}$. Work in Harsh Hot Environment: Risk Evaluation on Thermal Stress in a Farm during Green Pruning Activity. Biomed J Sci \& Tech Res 16(3)-2019. BJSTR. MS.ID.002865.

Keywords: Risk Evaluation, Heat, Agriculture, Wellbeing, Worker

Abbreviations: IPCC: Intergovernmental Panel on Climate Change; ENWHP: European Network for Workplace Health Promotion; PPD: Percentage of Dissatisfaction; WBGT: Wet Bulb Globe Temperature
ABSTRACT

Global warming is a phenomenon of rising average temperatures of the earth's surface that began to develop around the twentieth century. This is particularly important in working environments, where comfort is lower, and the effort required to perform certain activities contributes to increase body temperature. In outdoor environments there is no possibility of adopting preventive measures that substantially change unfavourable climatic conditions. The objective of this work is to demonstrate that it is possible to assess the health risk of workers from exposure to severe hot environment in outdoor farming operations. For the preparation of the study, phases 1 (observation) and 2 (analysis) were followed according to the indications of the technical standard UNI EN ISO 15265:2005. To measure the environmental parameters, two microclimate control units - (Babuc A) multi-data inquisition units were used. The main index calculated in the study was the WBGT.

This has been calculated with reference to UNI EN ISO 7243:2017. The workers who participated in the study were six. From the analysis of the data collected, no particular situations of risk of thermal stress emerged for the workers examined, except for the period around 11:00 AM when the WBGT, under the sun, reached values higher than $30^{\circ} \mathrm{C}$. In fact, the heart rates measured have always been below the theoretical maximum limit and with these it was possible to calculate the workload during the activity. The metabolic rate defined the type of activity as "moderate" and this evaluation was confirmed by three different evaluation methods (Screening, Analysis and Armband). During the study have been collected useful information to train and inform employers and workers, gives correct example on how this kind of risk should be assessed. Showing that already today it is appropriate to consider it with particular attention, in order to be able to adequately prevent it.

\section{Introduction}

Global warming is a phenomenon of rising average temperatures of the earth's surface that began to develop around the twentieth century. In the Fifth Assessment Report of IPCC (Intergovernmental Panel on Climate Change) and confirmed in the working documents on the sixth assessment, one of the most important climate changes expected is the increase of global temperatures. That is estimated to rise, between, 2 and 4 degrees by the end of the century [1]. This is particularly important in working environments, where comfort is lower, and the effort required to perform certain activities contributes to increase body temperature [2]. The risk of heat stress 
can occur both indoors and outdoors. In indoor environments, at least in some cases, it is possible to adopt measures that facilitate the lowering of the temperature inside the workplace, but this is not always possible because of the work requirements. In outdoor environments, such as construction sites and agricultural work, the heat source is the sun, which during the summer period can cause serious consequences on workers, especially in conjunction with high air humidity and no wind. In these environments, the risk of health effects often derives not only from high temperatures, but also from high workloads, inadequate organisation of work shifts, the absence of breaks and the impossibility of having risk prevention systems in place.

In these environments there is no possibility of adopting preventive measures that substantially change unfavourable climatic conditions [3]. Studies on the consequences of working in the heat, as well as on the health of workers, reduce the ability to work and thus productivity [4]. Reduced productivity and absence from work due to heat-related health effects necessarily generate financial costs for companies. In Germany, for example, during 2004 these costs were estimated at between $€ 0.7$ and 3.1 billion, while similar calculations for Australia in 2013 and 2014 indicated total losses of $€ 5.6$ billion [5]. Therefore, it is essential to identify the means that will allow workers to be more productive despite exposure to heat but, at the same time, will protect their health and safety. Despite increasing mechanization, agriculture is still characterized by a series of manual operations, which take place mostly outdoors and the heat in the workplace is difficult to mitigate, especially in the summer season. Direct exposure to the sun, rubbing, cutting, contact with plant protection products are the main risks of working in agriculture, causing stress from heat to heat stroke, dermatitis from contact to the development of melanomas $[6,7]$.

At European level, the ongoing HEAT-SHIELD project (https:// www.heat-shield.eu/) has the mission to investigate the negative impacts of workplace heat-stress perception on health and productivity of workers employed in five strategic European sectors (tourism, agriculture, manufacturing, construction and transportation), with the aim to develop preventive solutions to protect the health and productivity in the work place from excessive heat. For this reason, in Italy, since summer 2017, some case studies have been organized, gathering information on topics related to the heat-stress perception. The objective of this work is to demonstrate that it is possible to assess the health risk of workers from exposure to severe hot environment in outdoor farming operations. In this case, the experimental study referred to a farm during manual work in the fields.

\section{Materials and Methods}

The study was carried out in collaboration with the POLO for the Promotion of Health, Safety and Ergonomics in the Small and Micro enterprices of the Siena Province, partner of the European
Network for Workplace Health Promotion (ENWHP), in the framework of the memorandum of understanding signed with the Consortium of Vernaccia di San Gimignano. For the preparation of the study, phases 1 (observation) and 2 (analysis) were followed according to the indications of the technical standard UNI EN ISO 15265:2005 [8]. To carry out the observation a form is filled in that includes both objective parameters (air temperature, humidity, thermal radiation, air movements, physical workload, clothing) and subjective parameters (such as workers' opinions), to which a score is attributed. The scoring scales are designed so that the ideal score is "0". Scores with values between $-1 / 1$ are also considered acceptable, but if the value of the score is outside this range, a more in-depth analysis is considered necessary. The analysis: quantify the risk of thermal discomfort to determine an optimal organization of work and to determine if an "expertise" is needed (phase 3).

First of all, during the observation an analyses of the activity was carried out with particular attention to the description of the activities, the average and maximum duration, the period affected by the work situation, the number of workers exposed and the factors to be accurately quantified (air temperature, humidity, radiation, air movements, workload, clothing characteristics). Subsequently, the working situation is assessed taking into account the representative period relating to the climatic and working conditions and taking into account the external climatic conditions. The assessment shall also be carried out by measuring or estimating the mean and maximum values during the representative day(s) and calculating the indices according to the relevant standards the expected mean vote (PMV) and the expected percentage of dissatisfaction (PPD) [9] and the wet bulb globe temperature (WBGT- Wet Bulb Globe Temperature) [8]. On the day of the observation phase was carried out, informed consent was given to the workers in order to provide information on the study and allow them to join the project on an optional basis.

\section{Detection of Environmental Parameters}

To measure the environmental parameters, two microclimate control units - (Babuc A) multi-data inquisition units were used [10].

The instruments registered the following parameters:

a) $\quad \mathrm{Ta}=$ Air temperature $\left({ }^{\circ} \mathrm{C}\right)$

b) Tuv = ventilated wet bulb temperature

c) Tun $=$ Wet bulb temperature with natural ventilation $\left({ }^{\circ} \mathrm{C}\right)$

d) $\quad$ HR $\%=$ Relative humidity (\%)

e) $\quad-\mathrm{Tg}=$ Temperature of the Globo thermometer $\left({ }^{\circ} \mathrm{C}\right)$

f) - Va $=$ Air velocity $(\mathrm{m} / \mathrm{s})$

This control unit is fully programmable, acquires and stores data, allows to display on a monitor all measured and/or calculated quantities (e.g. WBGT). Through the connection to the computer 
it is possible to download the collected data in continuous, for the vision and the elaboration. The control units are equipped with the following probes to measure the parameters:

i. Psychrometric probe for measuring ambient air temperature and relative humidity (Ta, Tuv and HR\%);

ii. Globo thermometer probe for measuring the Globo thermometer temperature $(\mathrm{Tg})$ and for evaluating the average radiant temperature;

iii. Naturally ventilated wet bulb temperature probe (Tun), for calculating the WBGT index;

iv. Omnidirectional hot wire probe for measuring air velocity.

Furthermore, it should be specified that one control unit has been positioned so that for the entire duration of the survey was in the sun and the other in the shade, in order to allow the collection of data in both work situations. Close to these control units were also placed probes for continuous measurement of the microclimate parameters of the HOBO U30 NRC, in the period (June-September), air temperature, relative humidity, atmospheric pressure, temperature of the black globe, wind speed and direction, and solar radiation. The parameters measured and the characteristics of the probes complied with the indications of the technical standard UNI EN ISO 7726:2002 [11].

\section{Reference Values: the WBGT Index}

The main index calculated in the study was the WBGT. This has been calculated with reference to UNI EN ISO 7243:2017 [12]. The limit values of the WBGT index are included in the standard and based on data available in the scientific literature. If these values are exceeded, the thermal stress in the workplace must be reduced by suitable methods such as monitoring the environment, exposure time, the metabolic activity rate of the subject at work, the use of personal protection systems or proceeding with a detailed analysis of the thermal stress using more elaborate methods. [13,14] With regard to the contribution of clothing to the determination of the microclimate situation perceived by the worker, the standard provides a correction value to the detected WBGT in case of use of clothing with high thermal insulation.

\section{Physiological Parameters}

Two criteria were used to determine the physiological parameters: objective and subjective. In fact, during the course of the study, the subjective feelings of the workers were detected using a questionnaire that was administered at three different moments during the work shift: at the start, middle and end. On this occasion, information was collected on the clothing worn by the workers and used to calculate the thermal insulation of clothing in "Clo" according to UNI EN ISO 7730:2006 [9]. In addition, in order to highlight workers' responses to workplace exposures, a number of objective physiological parameters were measured and addressed to: (a) evaluate the physiological response of the workers examined during the execution of the work in specific microclimatic conditions;

(b) to assess the metabolic expenditure of workers during their working life.

For the determination of the energy metabolism of workers was followed the standard UNI EN ISO 8996:2005 [8]. The metabolic rate can be determined in different ways: the accuracy of the results, but also the costs of the study, increase from level 1 to level 4. In the study carried out, for the analysis of the activities of the workers and the determination of the respective metabolic rate, both the tables of level 1 (according to employment or work activity) and the method of continuous measurement of heart rate (level 3) were used. In order to verify the correlation between the activity carried out by the worker in a specific working condition (ascent/descent - sunshine/shadow) and the heart rate data registered, during the work, all information was collected to perform the next comparison. In particular, the following information has been provided for each worker:

a. Time of detection;

b. Operations carried out by specifying the working conditions (steep climb, medium climb, moderate climb, descent or breaks) and the exposure to the sun or shade;

c. Duration of activity.

\section{Thermal Effects}

Another standard has been followed to monitor the physiological parameters the UNI EN ISO 9886:2004. This standard describes the methods for measuring and interpreting the following physiological parameters: internal body temperature, skin temperature, heart rate and loss of body mass. In addition to the microclimatic parameters, the metabolic rate of activity and the isolation of clothing, measurements of actual water loss, heart rate and tympanic temperature.

\section{Instruments used and Purpose of Measurements}

The following instruments were used to measure the physiological parameters of workers:

A. Weightier (Joycare), with which the food and drink, workers and urine collected during the work shift were weighed, for the calculation of the actual water loss;

B. Thermometer (AccuSystem Genius 2), for measuring the tympanic temperature measured in four moments of the work shift (starting from the first measurement at the beginning of the activity was measured every two hours);

C. Wrist heart rate monitor (POLAR A360), for continuous measurement of heart rate at work and at rest; 
D. Armband (BODYMEDIA SenseWear pro), for the integrated measurement of metabolic load. This device was worn by only two workers.

\section{The Farm}

The study was carried out in a farm located in the municipality of San Gimignano. The farm is active in the wine sector since 1974

Table 1: Data of each worker involved in the survey.

\begin{tabular}{|c|c|c|c|c|c|c|c|}
\hline Workers & Sex (M/F) & Nationality & Age (years) & Height (m) & Weight (Kg) & BMI & Sup. Corp. (mq) \\
\hline Worker 1 (DM) & M & Senegal & 50 & 1,71 & 69,7 & 23,8 & 1,81 \\
\hline Worker 2 (FM) & F & Italian & 35 & 1,64 & 56,7 & 21,08 & 1,61 \\
\hline Worker 3 (RG) & M & Italian & 37 & 1,75 & 71,7 & 23,41 & 1,86 \\
\hline Worker 4 (SB) & M & Senegal & 53 & 1,79 & 71,4 & 22,2 & 1,89 \\
\hline Worker 5 (SMM) & M & Senegal & 48 & 1,84 & 77,9 & 23 & 2,00 \\
\hline Worker 6 (TE) & F & Italian & 40 & 1,62 & 59,9 & 22,8 & 1,63 \\
\hline
\end{tabular}

\section{Results}

\section{Preliminary Analysis}

On the $18^{\text {th }}$ of June 2018, the company's workers were carrying out manual operations in the vineyard. The observation phase was carried out on the basis of the UNI EN ISO 15265:2005 standard [8]. In addition, the purpose and stages of the investigation were explained to the workers; each worker signed the informed consent which was given before the investigation was carried out, as also provided for in the research protocol approved by the Ethics and covers an area of 180 hectares, of which 94 vineyards.

\section{Target Group}

The workers who participated in the study were six, two women and four men (three of whom were foreigners). Table 1 shows the main characteristics of each worker (Table 1).
Committee for Research of the University of Florence. Table 2 summarises the results of the observation conducted on the basis of the UNI EN ISO 15265:2005 standard and the score assigned to each parameter chosen [8] (Table 2). The ideal score, to decide if the environment is comfortable and no further analysis is necessary is " 0 ", but scores in the range $-1 / 1$ are considered acceptable. As can be seen, the scores reach values of " 2 " which therefore exceed the range of acceptability of the values. Given these results further investigation was conducted in the following days according to the standard protocol.

Table 2: Results of the observation conducted according to UNI EN ISO 15265 with the corresponding score.

\begin{tabular}{|c|c|c|}
\hline Parameter & Detected condition & Score \\
\hline Air temperature & Generally, between $25^{\circ} \mathrm{C}$ and $32^{\circ} \mathrm{C}$ & 1 \\
\hline Humidity & Normal & 0 \\
\hline Thermal radiation & Warm in the face after 2-3 minutes & 1 \\
\hline Air movements & Intensive work with arms and trunk: handling heavy objects, shoveling, cutting wood, \\
walking quickly or carrying a heavy load & 1 \\
\hline Physical workload & Long, heavy, slightly interfering with work & 2 \\
\hline Clothing & Heavy sweating, strong thirst, high rhythm work & 1 \\
\hline \multirow{2}{*}{ Workers' opinion } & Light sweating and discomfort, thirsty & 2 \\
\cline { 2 - 4 } & & \\
\hline
\end{tabular}

\section{Description of the Work Activity}

On the $3^{\text {rd }}$ of July 2018, an in-depth investigation was carried out at the farm, to assess the microclimate environment and the risk of thermal stress for workers. On that day, the workers undertook operations of tying and green pruning in the vineyard. Operations consisted of removal of unnecessary shoots from the various screws, using scissors and scythes; and arrangement of the shoots that were tied to the guardians of the vineyard (ligation). In order to carry out the activities, the workers followed the trend of the row and were arranged, in almost all the processes, one on each side. They also moved according to the slope of the vineyard and were arranged on the side most exposed to the sun in an alternating 
followed, which assigns to each garment the respective thermal resistance measured in "Clo" (1 Clo $=0.155 \mathrm{~m} 2 \mathrm{~K} / \mathrm{W}$ ) [9].

\section{Metabolic Load Assessment}

The work carried out during the survey has been subject to continuous observation and compared with the tables indicated in the technical standard UNI EN ISO 8996:2005 the workload would be "moderate" [8]. However, the analysis was deepened through the continuous monitoring of the heart rate (expressed in beats per minute) during the work, detected by heart rate monitors worn on the wrist throughout the shift by the single workers. The heart rate measured continuously for each worker is described in summary in Table 3. Using UNI EN ISO 8996:2005, it was possible to calculate the metabolic load expressed in watts/sqm of body surface, based on the detected HR, sex, weight and age of the subject [8]. The application of this method has led to the determination of metabolic rates (expressed in watts/sqm) for each activity, which have been reported in the table as an average based on time, for each worker (Table 4). Therefore, from the analysis of the variations in heart rate, it appears that the work carried out during the survey by the six workers can be classified, also through this method, as "Moderate work" confirming the analysis made by the method of screening. This was further confirmed by the analysis of the data collected with the ARMBAND monitor, worn by only two workers. The trend of the metabolic rate expressed in METs ( 1 MET $=3,5 \mathrm{H}_{2} \mathrm{O}$ $\mathrm{x} \mathrm{Kg} \mathrm{x} 1$ minute = 58.2 watts/sqm) of the two workers during the work shift, is graphically represented (Figure 1).

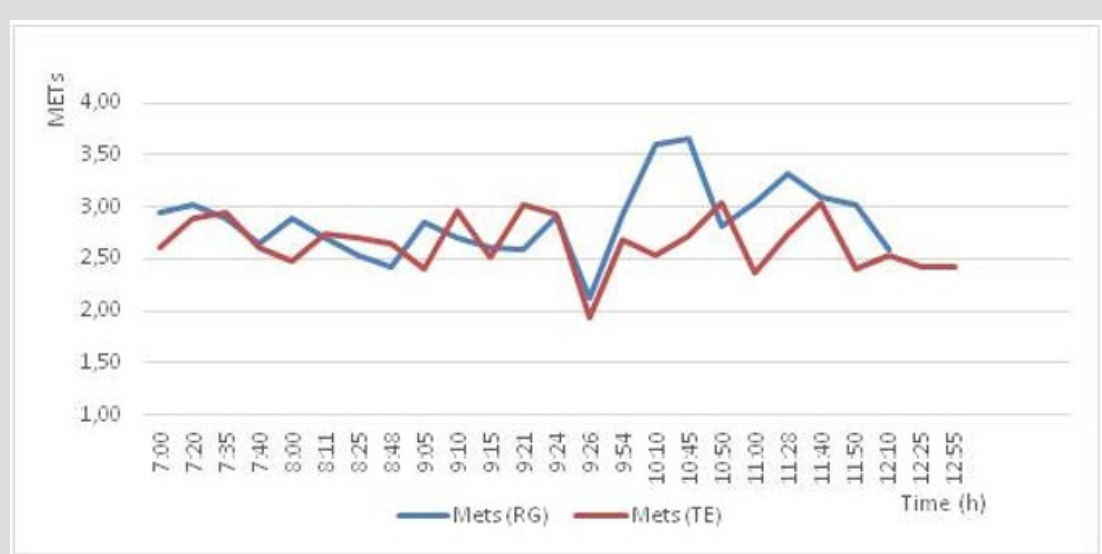

Figure 1: Trend in metabolic rate (MET) over time for the two workers who wore armband.

Table 3: Summary of heart rate data for each worker.

\begin{tabular}{|c|c|c|c|}
\hline Workers & HR a Relax & HR max Theoretic & HR Media \\
\hline Worker 1 (DM) & 77,6 & 170 & 109 \\
\hline Worker 2 (FM) & 79,3 & 185 & 101 \\
\hline Worker 3 (RG) & 71,3 & 183 & 100,7 \\
\hline Worker 4 (SB) & 72,3 & 167 & 115,9 \\
\hline Worker 5 (SMM) & 78,5 & 172 & 110,8 \\
\hline Worker 6 (TE) & 78 & 180 & 100,5 \\
\hline
\end{tabular}

Where the:

a) resting heart rate (resting HR) was calculated as the average of the lowest values measured up to the 5th percentile;

b) theoretical maximum heart rate (theoretical maximum heart rate) was calculated by removing the age from the value 220;

c) average heart rate (average HR) was calculated as the average of all the frequencies measured (per second) from the beginning to the end of the activity.

Table 4: Results of the metabolic load (watt/sqm) for each worker based on the flow of working time (min).

\begin{tabular}{|c|c|c|c|c|c|c|}
\hline \multirow{2}{*}{ Minutes } & \multicolumn{7}{|c|}{ Watt/mq } \\
\cline { 2 - 7 } & DM & FM & RG & SB & SMM & TE \\
\hline 0-120 (06:00-08:00) & 208 & 90 & 235 & 283 & 276 & 135 \\
\hline 121-180 (08:01-09:00) & 189 & 157 & 185 & 232 & 266 & 144 \\
\hline $181-240(09: 01-10: 00)$ & 229 & 150 & 170 & 266 & 254 & 147 \\
\hline $241-300(10: 01-11: 00)$ & 255 & 152 & 206 & 261 & 246 & 161 \\
\hline $301-420(11: 01-13: 00)$ & 216 & 143 & 186 & 242 & 251 & 152 \\
\hline
\end{tabular}




\section{Microclimatic Data}

The two microclimate control units, positioned respectively in the sun and in the shade, measured the parameters of ambient temperature, relative humidity, naturally ventilated wet bulb temperature, Globo thermometer temperature and WBGT throughout the working shift. The data collected by both controllers are represented graphically for each parameter (Figures 2a2e). The microclimate parameters measured continuously were analyzed and, taking into account the activity carried out over time by individual workers (type of activity and exposure to the sun and shade) and changes in the metabolic rate of each (change in FC, sex, age, weight and height) it was possible define, for each, the limit value of the WBGT according to UNI EN ISO 7243:2017 and compare it with the value of the same parameter measured continuously by the control units [12]. Must be pointed out that in all observations, the WBGT limit always exceeded at the end of the shift, when the conditions of radiation and air temperature become higher.

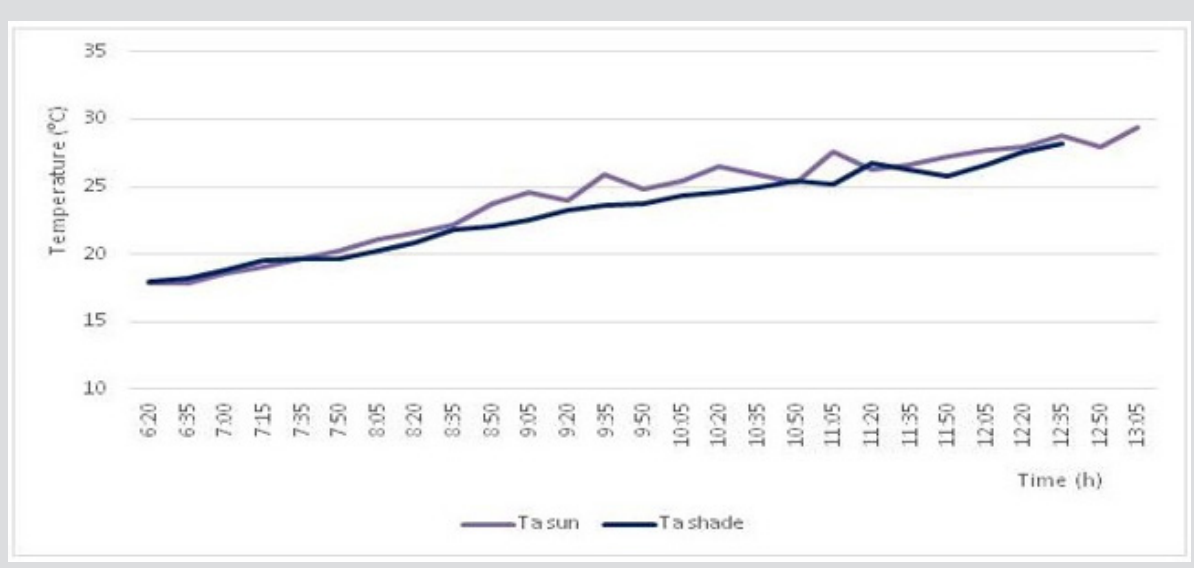

Figure 2a: Ambient temperature measured in the sun and shade.

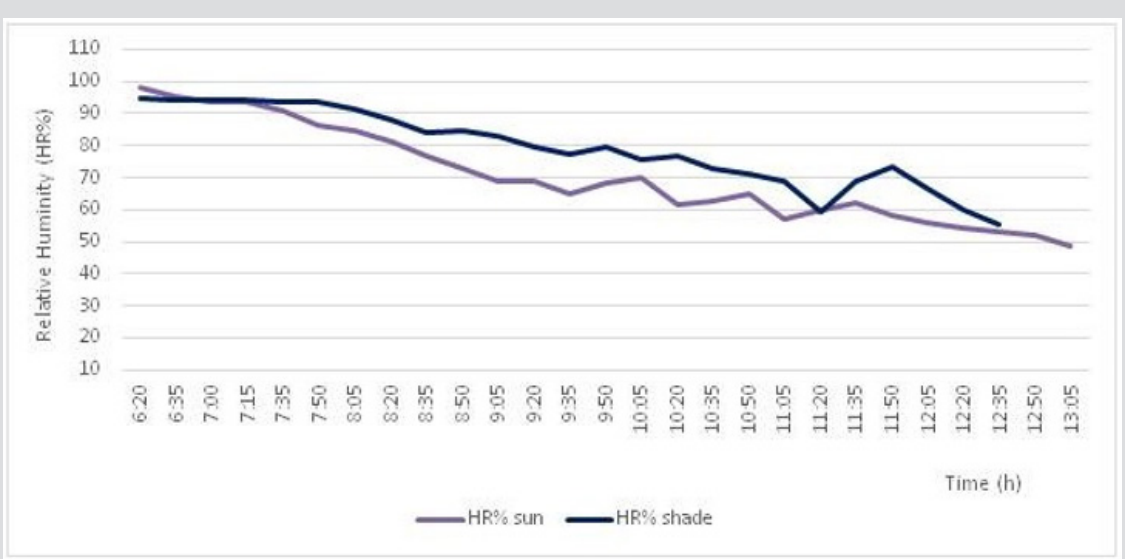

Figure 2b: Relative humidity measured in the sun and shade.

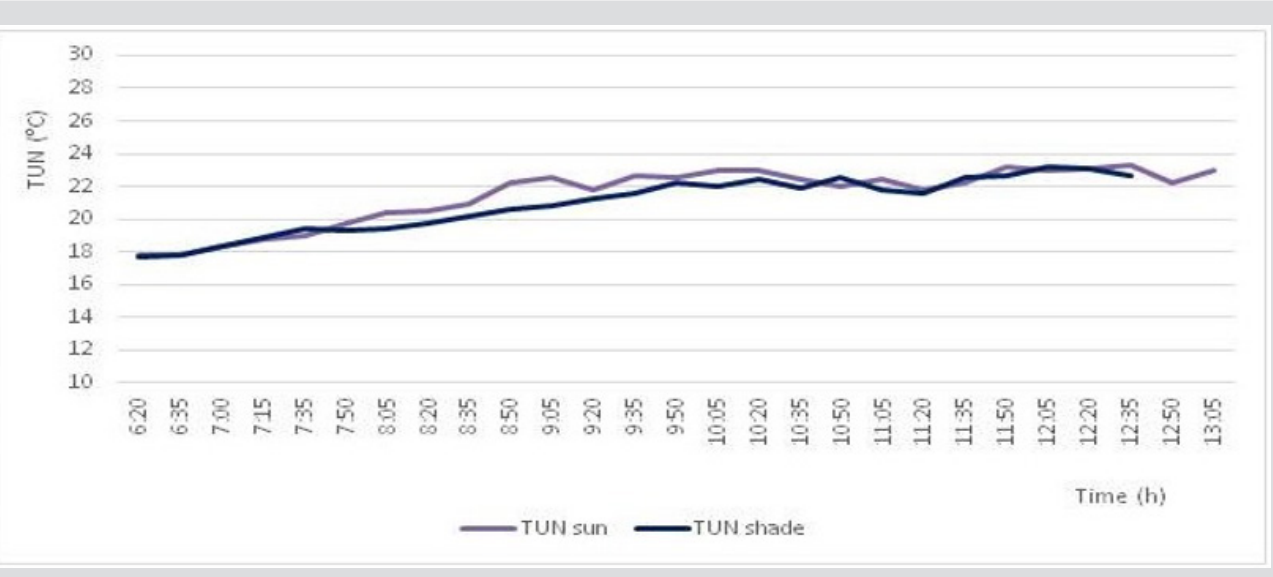

Figure 2c: Relative humidity measured in the sun and shade. 


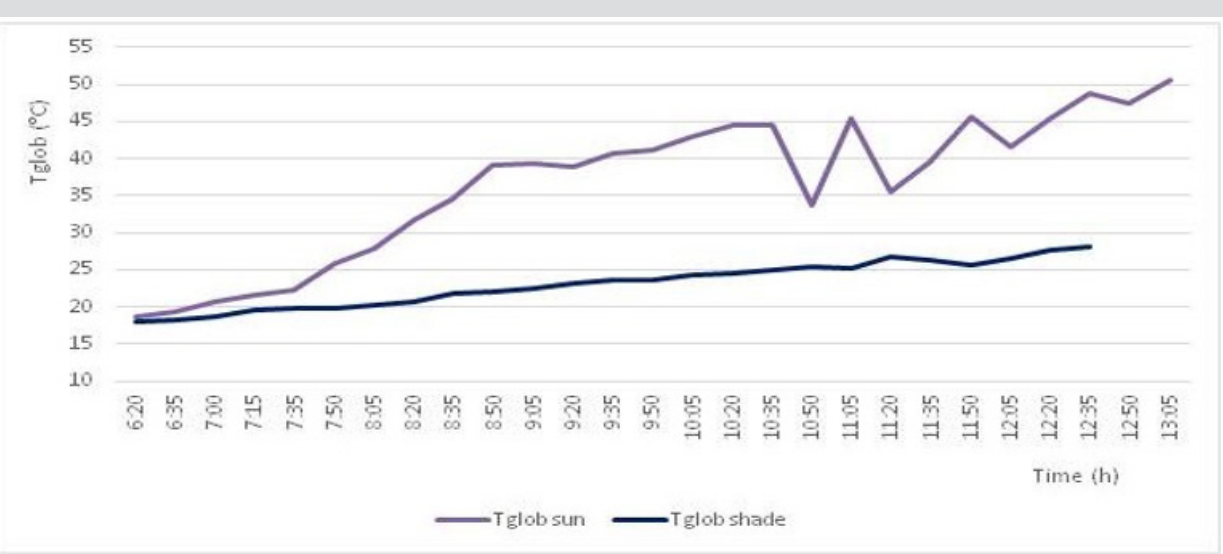

Figure 2d: Globo thermometer temperature measured in the sun and shade.

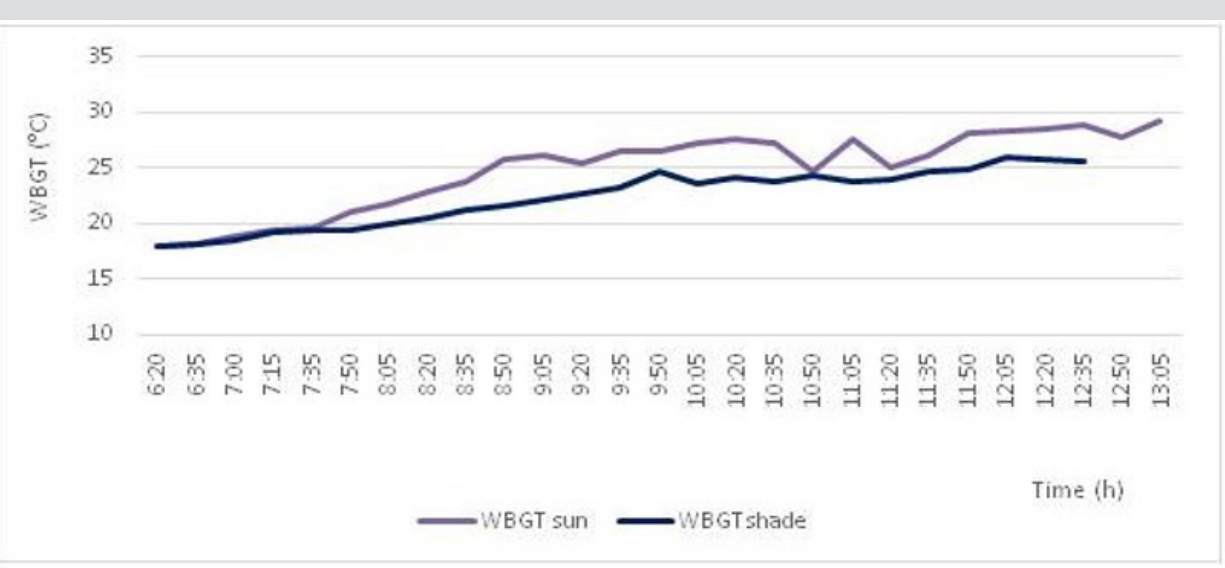

Figure 2e: WBGT detected in the sun and shade.

\section{Physiological Response of Workers}

For the calculation of the actual water loss during the work were collected the initial weight of the subject, the amount of food and liquids introduced and the amount by weight of urine and faeces expelled. The following table summarises the information collected for each worker and the relative value of actual water loss (Table 5). The total water loss was determined by adding to the initial weight of the subject the relative amount of food and drink introduced and subtracting the weight of any urine and faeces expelled. The water loss observed by the various workers at the end of the shift is limited to less than two litres, always below the limit value laid down in the UNI EN ISO 9886:2004 standard [15]

Table 5: Information for the determination of the total and actual water loss value for each worker.

\begin{tabular}{|c|c|c|c|c|c|}
\hline Workers & Initial weight (kg) & Food/liquids (kg) & Urine / faeces (kg) & Final weight (kg) & Total water loss \\
\hline Worker 1 (DM) & 69,7 & 3,2 & 1,73 & 70,4 & 0,77 \\
\hline Worker 2 (FM) & 56,7 & 2,45 & 1,78 & 56,4 & 70,2 \\
\hline Worker 3 (RG) & 71,7 & 2,23 & 2,03 & 71 & 1,7 \\
\hline Worker 4 (SB) & 71,4 & 1,58 & 0,33 & 7,65 \\
\hline Worker 5 (SMM) & 77,9 & 2,17 & 1,73 & 5,6 & 1,74 \\
\hline Worker 6 (TE) & 59,9 & 0,75 & 0,33 & 59,3 & 1,02 \\
\hline
\end{tabular}

and in other studies carried out on the subject [16-18]. This is in line with relatively moderate exposure to heat levels and metabolic activity rate values. Another physiological parameter detected was the value of the tympanic temperature. This was measured at four different moments during work. The values of the temperatures found are shown in the Table 6. The tympanic temperatures have had the same trend for all workers: they have gradually increased, and then decreased during the last measurement, made at the end of the work, at the company headquarters and not in the field. Only for three workers the measurement carried out at 11:00 AM, in the hottest period of the day with the WBGT exceeding the calculated limit value, the limit of $38^{\circ} \mathrm{C}$ set by UNI EN ISO 9886:2004 was limit value, the limit of exceeded slightly [15]. 
Table 6: Tympanic temperatures $\left({ }^{\circ} \mathrm{C}\right)$ measured at four different moments during the work shift.

\begin{tabular}{|c|c|c|c|c|}
\hline Workers & $\begin{array}{c}\text { Measurement 1 } \\
\text { (start) }\end{array}$ & $\begin{array}{c}\text { Measurement 2 } \\
\text { (9 o'clock) }\end{array}$ & $\begin{array}{c}\text { Measurement 3 } \\
\text { (11 o'clock) }\end{array}$ & $\begin{array}{c}\text { Measurement 4 } \\
\text { (end shift) }\end{array}$ \\
\hline Worker 1 (DM) & 35,8 & 37,3 & 38,3 & 36,9 \\
\hline Worker 2 (FM) & 35,8 & 36,6 & 37,8 & 37,1 \\
\hline Worker 3 (RG) & 35,8 & 37,3 & 38,3 & 36,9 \\
\hline Worker 4 (SB) & 35,8 & 37,3 & 38,3 & 36,9 \\
\hline Worker 5 (SMM) & 35,5 & 37 & 37 & 36,6 \\
\hline Worker 6 (TE) & 35,8 & 36,6 & 37,8 & 37,1 \\
\hline
\end{tabular}

\section{Discussion}

From the analysis of the data collected, no particular situations of risk of thermal stress emerged for the workers examined, except for the period around 11:00 AM when the WBGT, under the sun, reached values higher than $30^{\circ} \mathrm{C}$. In fact, the heart rates measured have always been below the theoretical maximum limit and with these it was possible to calculate the workload during the activity. The metabolic rate defined the type of activity as "moderate" and this evaluation was confirmed by three different evaluation methods (Screening, Analysis and Armband). Thanks to the determination of the metabolic load, it was possible to calculate the WBGT limit for each worker who, compared with the WBGT detected by the microclimate control units, showed higher levels only in the periods of the shift most exposed to the heat. Total water loss for all workers was contained and always below the limit values (1.25 l/h for acclimatized subjects), while tympanic temperatures exceeded the limit value of 38 for three workers at 11:00 am. The study showed elements of "strain" of workers only in the last period of the working day, the increase in heat, but did not highlight health risks or high critical microclimate or heat stress.

The study showed a situation of absence of thermal risk, in relation to the activity carried out by the workers, for exposure to the microclimate conditions present in the specific day of the study. However, it should be considered that the climatic trend in the period under study was characterized by temperatures that were not excessively high, unlike what was observed in the previous years. Therefore, it is clear that there is a need to maintain constant attention on the phenomenon also for the next few years, in view of the climate change underway, which is expected to cause further global warming. It is therefore essential to assess in detail the various factors that can cause heat stress even in outdoor work, so as to provide increasingly effective tools to assess the risk of workers and consequently implement the necessary preventive measures to limit this risk. The data collected in the study and the results obtained can also be used to improve the information/ training interventions of workers in order to make them aware of risk situations; this is especially true for workers who are hired under atypical employment contracts, often for a fixed period, and are therefore less prepared and acclimatized to deal with these work situations. In this regard, the origin of the workers should not be under estimated, as they are often foreigners and may present difficulties in understanding rules, as well as different habits and ways of working from workers who have already been in the work cycle for some time.

In order to respond to these difficulties training and information initiatives aimed at both employers and individual workers, providing real-time information on risks can be a good starting point. The joint planned prevention systems should consider:

i) the reorganisation of work, for example by considering the execution of work at times that avoid exposure to the sun during the hottest hours;

ii) the presence of breaks during the activity carried out in appropriate environments, which even if short, allow workers to cool down, hydrate, restore the thermal balance and physiological recovery;

iii) the need for progressive acclimatisation during systematic exposure to high temperatures in order to adapt certain physiological parameters.

The methods of assessing the risk of heat stress in a severe hot environment used in this study can be used by employers and their consultants to properly carry out the risk assessment for all those workers working outdoors, thus providing valuable support for the identification of any prevention measures, as well as providing a basis for the formulation of business improvement programs.

The results obtained can provide valuable support for all information initiatives for workers exposed to a severe hot environment, initiatives that may involve public bodies, producers' associations, trade associations and trade unions. Finally, also the bodies responsible for control in the workplace can use the methods and results obtained to plan and improve supervisory measures, also verifying the completeness and adequacy of the risk assessment by physical agents. The best knowledge of possible situations of risk from microclimate in the activities carried out in the summer in agriculture, can also help the prevention services to provide assistance to all companies and workers, to implement the best preventive solutions to limit this risk. The study carried out is a good example for a correct assessment of this risk, showing that already today it is appropriate to consider it with particular attention, in order to be able to adequately prevent it. At last, in order to disseminate and share these local initiatives at European level it is important that such initiatives are supported by the POLO for the Promotion of Health, Safety and Ergonomics in the PMMI of 
the Province of Siena, in full collaboration with the ENWHP. This guarantees quality and gives the possibility to put the results of the various experiences in the perspective of health promotion and improvement of working conditions.

\section{Acknowledgement}

This paper is part of the master's degree research of Serena Iacopini. The study also saw the collaboration with several HeatShield researchers which received funding from the European Union's Horizon 2020 research and innovation programme under grant agreement No. 668786.

\section{References}

1. Pachauri RK, Allen MR, Barros VR, Broome J, Cramer W, et al. (2015) Climate Change 2014: Synthesis Report. Contribution of Working Groups I, II and III to the Fifth Assessment Report of the Intergovernmental Panel on Climate Change. IPCC, Geneva, Switzerland.

2. Schulte PA, Chun H (2009) Climate change and occupational safety and health: establishing a preliminary framework. J Occup Environ Hyg 6(9): 542-554.

3. Camilo M, Bénédicte D, Caldwell IR, Farrah E, Rollan C Geronimo, et al. (2017) Global risk of deadly heat. Nature Climate Change 7: 501-506.

4. Brenda Jacklitsch, W Jon Williams, Kristin Musolin, itor Coca, Jung-Hyun Kim, et al. (2016) Criteria for a Recommended Standard Occupational Exposure to Heat and Hot Environments. Heat stress in the workplace.

5. Ioannou LG, Tsoutsoubi L, Samoutis G, Lucka Kajifez, Glen P Kenny, et al. (2017) Time-motion analysis as a novel approach for evaluating the impact of environmental heat exposure on labor loss in agriculture workers. Temperature (Austin) 4(3): 330-340.

6. Kaskel P, Lange U, Sander S, Huber MA, Utikal J, et al. (2015) Ultraviolet exposure and risk of melanoma and basal cell carcinoma in Ulm and Dresden, Germany. J Eur Acad Dermatol Venereol 29(1): 134-142.

7. Kachuri L, Harris MA, MacLeod JS, Tjepkema M, Peters PA, et al. (2017) Cancer risks in a population-based study of 70,570 agricultural workers: results from the Canadian census health and Environment cohort (CanCHEC). BMC Cancer 17(1): 343.

\section{ISSN: 2574-1241}

DOI: 10.26717/BJSTR.2019.16.002865

Giuseppe Masanotti. Biomed J Sci \& Tech Res

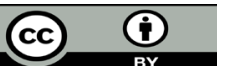

This work is licensed under Creative

Commons Attribution 4.0 License

Submission Link: https://biomedres.us/submit-manuscript.php
8. (2005) UNI EN ISO. Ergonomics of the thermal environment - Risk assessment strategy for the prevention of thermal stress or discomfort in working conditions, UNI EN ISO 15265: February 2005.

9. (2006) UNI EN ISO. Ergonomics of the thermal environment - Analytical determination and interpretation of thermal comfort using calculation of the PMV and PPD indices and local thermal comfort criteria UNI EN ISO 7730: February 2006.

10. Ismail AR, Rani MRA, Makhbul ZKM, Sopian K, Deros BM (2009) Thermal Comfort Assessment and Optimization of Environmental Factors by Using Taguchi Method. American Journal of Applied Sciences 6 (9): 1731-1741.

11. (2002) UNI EN ISO. Ergonomics of the thermal environment Instruments for measuring physical quantities. UNI EN ISO 7726: January 2002.

12. (2017) UNI EN ISO. Ergonomics of the thermal environment - Assessment of heat stress using the WBGT (wet bulb globe temperature) index UNI EN ISO 7243: November 2017.

13. Dell'Isola M, Frattolillo A, Palella B, Riccio G (2012) Influence of Measurement uncertainties on the thermal environment assessment. International Journal of Thermophysics 33(8-9): 1616-1632.

14. Bernard TE, Iheanacho I (2015) Heat index and adjusted temperature as surrogates for wet bulb globe temperature to screen for occupational heat stress. J Occup Environ Hyg 12(5): 323-333.

15. (2004) UNI EN ISO. Ergonomics - Evaluation of thermal strain by physiological measurements. UNI EN ISO 9886: July 2004.

16. Binazzi A, Levi M, Bonafede M, Bugani M, Messeri A, et al. (2019) Evaluation of the impact of heat stress on the occurrence of occupational injuries: Meta-analysis of observational studies. Am J Ind Med 62(3): 233-243.

17. Borg DN, Costello JT, Bach AJ, Stewart IB (2017) Perceived exertion is as effective as the perceptual strain index in predicting physiological strain when wearing personal protective clothing. Physiol Behav 169: 216-223

18. El-Shafei DA, Bolbol SA, Awad Allah MB, Abdelsalam AE (2018) Exertional heat illness: knowledge and behavior among construction workers. Environ Sci Pollut Res Int 25(32): 32269-32276.

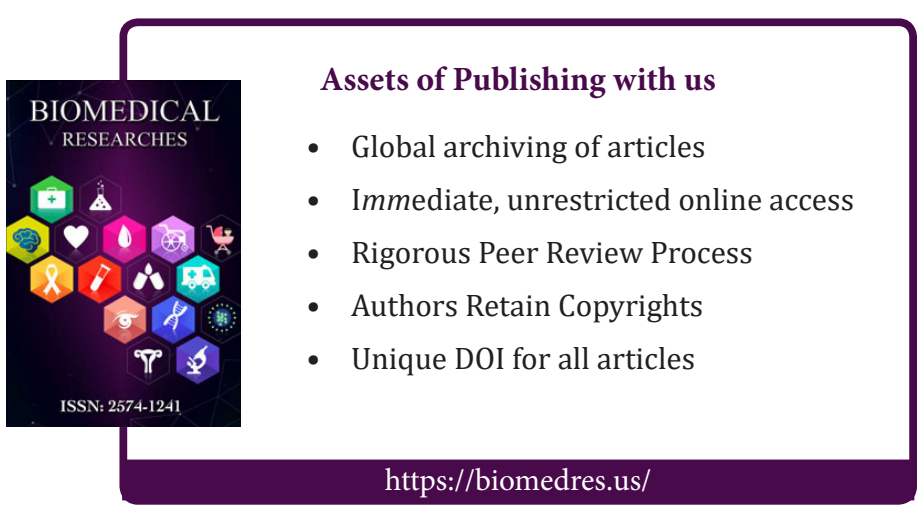

